\title{
Marko Dragić
}

mdragic@ffst.hr

\section{Vuk u folkloru Hrvata}

\begin{abstract}
Dragić Marko, Vuk u folkloru Hrvata (Wolf in the Folklore of Croats). „Poznańskie Studia Slawistyczne” 3. Poznań 2012. Adam Mickiewicz University Press, pp. 45-59. ISBN 978-83-232-2473-0. ISSN 2084-3011.
\end{abstract}

The paper focuses on the significant role of wolf in the Croatian folklore that has been confirmed by a series of analyses over the thirty contemporary original field records. The socalled wolf processions were still performed in many places of the country just before the Homeland War in 1991. Often described in a word vukavarski, the processions were always initiated by an act of killing the wolf since the animal was traditionally assumed as a symbol of evil and subsequently as a cause of severe damage. In order to celebrate such an act, the wolf killer, accompanied by a small group of hunters, had to march through the village. The group was obliged to sing or recite spells, derived from an apotropaic rite, in front of the country houses. As for the hosts, they were satisfied to receive the procession (such a satisfaction was usually expressed by different rewards) since all the neighbourhood had got rid off another dangerous animal.

Keywords: wolf processions, spells, wedding wolves, wolves from Deževice, apotropaic character

I tako se još uvijek onim potajnim daklem, možda malo i otvrdlim, čulima sporazumijevamo sa svim stvarima, bićima i duhovima u tom otajstvenom i jedinstvenom Božjem svijetu. Pogledaj ovo kamenje. Čim padne mjesečina vidjet ćeš kako se tihano nadimlje $i$ diše. U svakom kamenu po jedan duh, u svakoj jeli vila, na svakom groblju strašilo, na svakom putu nagaz, u svakoj jami jauk, na svakom izvoru čarolija. I tamo sve do zvijezda i sazviježđa, do neba i nebesa, daklem, beskrajni svijet duhova ogrnut golemim plaštem Božje ljubavi. Ako nam to oduzmeš čim ćeš nas zaodjenuti.

Ivan Raos, Prosjaci i sinovi

\section{Uvod}

U Herodotovoj Povijesti spominje se pleme Neuri na dalekom sjeveru. Pripadnici toga plemena svake su se godine nekoliko puta pretvarali u vuka. Neki istraživači taj Herodotov zapis tumače kao vjerovanje toga plemena u vukodlake, a drugi istraživači smatraju da je Herodot pisao o drev- 
nim slavenskim maskiranim običajima po kojima su mladići u skupinama hodali po naseljima noseći maske vuka. Međutim, prijepori su o Neurima kao protoslavenima.

Vuk je u tradiciji Južnih Slavena i nekih drugih indoeuropskih naroda demonska životinja. U Hrvata su uz vuka vezani razni ophodi i basme. Ti su običaji veoma stari, a u današnje vrijeme gotovo su iščezli. Do osamdesetih godina 20. stoljeća, a ponegdje, primjerice u Unešiću, sve do početka Domovinskoga rata, izvodili su se kroz cijelu godinu.

Nedostatni su podatci o tim ophodima. Znanstvenici ih, uglavnom, navode usputno. Vučare spominje i Petar Grgec, ali ništa o njima ne piše ${ }^{1}$. Tvrtko Čubelić spominje vukare i o njima navodi dvije rečenice ${ }^{2}$. Ti su ophodi i basme i danas u narodnom pamćenju.

U kršćanskoj je tradiciji legenda o svetom Franji i vuku koji je činio mnoga zla u okolici Gubbija. Sveti Franjo vuka je nazvao bratom vukom i zauzeo se za njega kao Božje stvorenje koje ne zna bolje činiti te se angažirao da ga pripitomi ${ }^{3}$. Vitomir Belaj navodi da vukovi u hrvatskoj tradiciji pripadaju i svetom Juri jer ih on može usmjeravati ${ }^{4}$.

Unatoč iznimnom mjestu koje vuk zauzima u folkloristici Hrvata i drugih naroda ta je tema nedostatno istražena. Neki etnolozi, antropolozi i filolozi navode pogrešne podatke, primjerice o vremenu kada su se izvodili vukarski ophodi te kada su se ti ophodi prestali izvoditi. Stoga se u ovom radu navode izvorni terenski zapisi studenata filozofskih fakulteta u Splitu i Mostaru. Ti zapisi nastali su na području Republike Hrvatske i Bosne i Hercegovine pod mentorstvom autora ovoga rada. U radu je tridesetak takvih primjera koji se prvi put publiciraju.

\section{Vučarski/vukarski ophodi i basme}

Vučari su maskirani ophodnici koji su u skupinama od tri do četiri čovjeka, nakon što bi ubili vuka, oderali mu kožu, nataknuli je na kolac, napunili slamom i okitili je svilom, vunom i šarenim papirima, hodali po

\footnotetext{
${ }^{1}$ P. Grgec, Hrvatske narodne pjesme, Zagreb 1943, str. 151.

${ }^{2}$ T. Čubelić, Povijest i historija usmene narodne književnosti, Zagreb 1990, str. 77.

${ }^{3}$ Leksikon ikonografije, liturgike i simbolike zapadnog kršćanstva i Uvod u ikonologiju Radovana Ivančevića, ur. A. Badurina, Zagreb 1990, str. 588.

${ }^{4}$ V. Belaj, Hod kroz godinu, Zagreb 1998, str. 190.
} 
svom i susjednim selima glasno pjevajući i tražeći darove za ubijenoga vuka. Vučare su za ubijenoga vuka darivali slaninom, mesom i drugim prehrambenim proizvodima od kojih bi pravili gozbu na kraju ophoda ${ }^{5}$. Tim ophodima i basmama željelo se ,spriječiti” vuka da prilazi domovima i štalama.

Basma je stručni naziv za usmeno-retorički oblik koji se pri magijskom obredu šaputao/recitirao, pjevušio u želji da se čovjeka, njegovu imovinu i stoku zaštiti ili oslobodi od bolesti, demonskih sila i vremenskih nepogoda, da djevojci dođe i/ili oženi je njezin odabranik, da za vrijeme sušnih proljetnih i ljetnih dana božanstvo udijeli kišu i tako spasi ljetinu. U stručnoj su uporabi za basmu sinonimi bajalica, egzorcizam i zaklinjanje, a narodni su nazivi bajalica i bajavica. Neki su filolozi i leksikolozi s pravom ustvrdili da je basma čarobni tekst koji se izgovara pri bajanju (čaranju, vračanju $)^{6}$. Basme pripadaju magijskoj književnosti ${ }^{7}$. Ostvaruju se stihovima i prozom. U njima se prepleću mitski i vjerski elementi ${ }^{8}$.

Basme koje su recitirali/pjevali vučari u tim ophodima nazivane su vučarske/vukarske pjesme. Pjesmom se poziva domaćina da vuku poda sočice, varice, jarice, vunice, junice, slanine kako ne bi silazio s planine jer nije dobar kod kuće?

Radmila Kajmaković navodi da su vučarske obrede u livanjskom kraju u jesen izvodili Hrvati i Srbi ${ }^{10}$, a pišući o vučarima u širokobriješkom kraju navodi da se taj običaj izgubio nakon Drugog svjetskoga rata kada je

${ }^{5}$ M. Palameta, Usmeni narodni teatar u Hercegovini, Mostar 1996, str. 63-65.

${ }^{6}$ T. Ćubelić, Usmena narodna retorika i teatrologija, Zagreb 1970, str. 58.

${ }^{7}$ Kod najstarijih civilizacija bila je razvijena magijska književnost. Toj književnosti pripadaju mezopotamske inkantacije i molitve magijskim izvorima moći: vatri, soli, vodi. Drevni su Egipćani, također, bajanjem liječili i od demonskih sila štitili ljude i stoku (M. Višić, Književnost drevnog Bliskog istoka, Zagreb 1993, str. 9). Antički grčki filozof Gorgija (493.-370. pr. Krista) ukazao je na magijsku moć riječi proglasivši je vlastodršcem „koji najmanjim i najneupadljivijim organom postiže najčudesnija djela” (T. Čubelić, Povijest $i$ historija..., str. 280). U Bibliji je govorništvo dar Božji (S. Botica, Biblija i hrvatska kulturna tradicija, Zagreb 1995, str. 107).

${ }^{8} \mathrm{O}$ tome više: M. Dragić, Basme u hrvatskoj usmenoj retorici i izvedbi, u: Batkański folklor jako kod interkulturowy, t. 1, ur. J. Rękas, Poznań 2011, str. 75-98.

${ }^{9}$ Cf. Hrvatska usmena književnost Bosne i Hercegovine: lirika, epika, retorika, prir. M. Dragić, Hrvatska književnost Bosne i Hercegovine u 100 knjiga, Sarajevo 2006, str. 73.

${ }^{10}$ R. Kajmaković, Maskirani ophodi, „Glasnik zemaljskog muzeja. Etnologija”, sv. XV-XVI, Sarajevo 1961, str. 230. 
država počela isplaćivati nagrade za ubijenoga vuka. Tada su počeli ophodi $\mathrm{s}$ ubijenom lisicom, ali te obrede nisu pratile pjesme/basme ${ }^{11}$.

U Donjim Vinjanima održavali su se vučarski ophodi nakon što bi lovci u lovu ubili vuka, te su pjevali: „Evo vuka, s planine, / dajte njemu slanine. / Evo vuka preko mosta, / dajte njemu svega dosta". Na taj su način vučari od mještana tražili darove jer su ubili vuka i spasili im stada ${ }^{12}$.

U minulim vremenima, kad se narod bavio stočarstvom, veliko su zlo činili vukovi, spuštajući se u selo gdje bi često poklali mnoge ovce i koze. Kad bi se vuk pojavio, lovci bi ga ubili, oderali kožu s njega, a unutra natrpali slame ili sjena. Potom bi ga stavili na veliki kolac i tako išli od kuće do kuće pucajući iz pušaka u zrak i pjevajući ${ }^{13}$ :

Evo vule iz planine,

darujte mu kil slanine (krmetine),

pleće mesa bravetine.

Darujte mu runo vuno,

da ne kolje ovce žune.

Evo vule mrke dlake,

pa darove prima svake.

Nije vule za držanje,

nego duže putovanje.

Nakon primljenih darova skupina bi se zahvalila.

Ova snaša lipa struka,

darovala našeg vuka.

Oda su ga darovali,

od Boga se radovali.

Da bi vule sluša ćaće,

ne bi odan nosa gaće.

Da bi vule sluša mame,

ne bi onda nosa slame.

${ }^{11}$ Idem, Narodni običaji stanovništva Lištice, „Glasnik zemaljskog muzeja Bosne i Hercegovine. Etnologija”, Nova serija, sv. XXIV/XXV, Sarajevo 1969/1970, str. 312-313.

${ }^{12}$ U Donjim Vinjanima kod Imotskoga u svibnju 2007. god. zapisala je Branka Despotušić, a kazao joj je Mijo Raić (rođ. 1957. god.) podrijetlom iz Doljana (Zahumlja), a živi u Pločama. Rkp. FF ST sv. 2007., S. (Objašnjenja skraćenica rukopisne zbirke se nalaze u Izvorima priloženima na kraju rada).

${ }^{13}$ I. Furčić, Narodno stvaralaštvo šibenskoga područja, Šibenik 1988, str. 205. 
Ovi vule ne zna ćaću,

liva vino u buraću.

Ovi vule niza dolac,

ubija ga [po imenu] lovac ${ }^{14}$.

Furčić je zapisao da se taj običaj prakticirao i u osamdesetim godinama dvadesetoga stoljeća ${ }^{15}$.

Domaćine, rode moj,

evo vuka pred tvoj dvor.

Goni vuka od kuće,

nije dobar kod kuće.

Podaj vuku sočice,

podaj vuku varice,

da ne kolje jarice.

Podaj vuku vunice,

da ne kolje junice.

Podaj vuku slanine

da ne slazi s planine.

Podaj vuku svašta dosta,

da ne kolje pokraj mosta ${ }^{16}$.

Slična je i pjesma iz Trbounja kod Drniša:

Domaćine od kuće,

evo vuka kod kuće.

Tirajte ga od kuće,

nije dobar kod kuće.

Podajte mu šenice,

da ne kolje telice.

Podajte mu slanine,

da ne silazi s planine.

Podajte mu zopčice,

da ne kolje ovčice ${ }^{17}$.

${ }^{14}$ Ibidem, str. 197.

${ }^{15}$ Ibidem, str. 205.

${ }^{16}$ Adrijana Pandža 2002. g. zapisala u Orašinama u Raškoj gori kod Mostara. Kazala Iva Leto, djev. Šunjić (rođ. 1934. g.). Rkp. FF MO sv. 2002., S.

${ }^{17}$ Zapisala je svibnja 2006. g. Marina Matić u Trbounju kod Drniša, a kazao joj je Ive Matić (rođ. 1927. g). Rkp. FF ST sv. 2006., S. 
Špiro Kulišić spominje izreku Podaj vuku varice, da ne kolje jarice i pri tome objašnjava panspermijsko značenje varice koja se prinosila kao žrtva. Varica ${ }^{18}$ se sprema od brašna svakoga žita ili se u nju stavlja po zrno svake žitarice te se njome posipaju ljudi, stoka, brodovi, ulišta i dr. Namjera je toga obreda apotropejska i panspermijska ${ }^{19}$.

Milovan Gavazzi navodi da su se vukarski obredi izvodili „u doba oko Božića pa do Poklada”,20.

U Lici je bio običaj da ljudi naoružani vilama, sjekirama i puškama organiziraju hajke na vukove. Ti su se ljudi nazivali vukari, a pjevali su vukarske pjesme kako bi od kuće i stada odagnali vuka:

Domaćine od kuće,

evo vuka kod kuće,

o-o-o-o-oj!

Tirajte ga od kuće,

podajte mu suva mesa,

da vam tora ne pritresa.

Podajte mu slanine,

da ne slazi s planine.

Podajte mu šenice,

da ne kolje telice.

Podajte mu zobčice,

da ne kolje ovčice.

Dajte, vuku vlasa,

da ne kolje pasa.

Kiti snašo, mrka vuka,

da t' je ćerka lipšeg struka ${ }^{21}$.

Vukari su i sljedećim magijskim katrenom odgonili vuka od kuće:

Mrki vuče, kojo ti je majka,

kojo majka, a kojo sestrica?

${ }^{18} \mathrm{U}$ stolačkom je kraju varica naziv za koljivo (varivo od mesa zaklane stoke).

19 Š. Kulišić, Značaj slovensko-balkanske i kavkaske tradicije u proučavanju stare slovenske religije, knj. 9, Sarajevo 1973, str. 155.

${ }^{20}$ M. Gavazzi, Godinu dana hrvatskih narodnih običaja, Zagreb 1991, str. 220.

${ }^{21}$ Zapisala je 2004. g. na području Gospića, Kosinja i Perušića Lidija Đerek od svoje obitelji: bake, djeda, ujni i rođakinja. Rkp. FF ST sv. 2004., S. 
Majka mi je gora i planina,

a sestrica po gori maglica ${ }^{22}$

Tim su stihovima vukari uspostavili svojevrstan kontakt s vukom te mu nakon pitanja tko su mu majka i sestrica, sugestivno odgovaraju da mu je majka gora i planina, a sestrica po gori maglica. Tim su metaforičnim sugestijama vuka tjerali u goru, planinu i maglicu.

Vukari su u Kruševu kod Zadra magijskim riječima u svojim pjesmama htjeli udobrovoljiti vuka, tražeći od domaćina da vuku dade slanine, runo vune, svega dosta; da ne priđe preko mosta, da ne kolje ovce žune ${ }^{23}$.

Vučarske/vukarske pjesme po svojoj poetici pripadaju basmama kojima se liječe ljudi, životinje te se iz njihovih domova, štala i imanja odgone demonske sile.

Vučari su bili lovci koji su ciljano odlazili u lov na vuka jer je ubijao blago. Kad bi vuka ubili, lovci bi išli po obližnjim selima i zaseocima obučeni u lovačke odore, s tim da je glavni lovac nosio na kolcu nabijenu kožu (,mišinu”) vuka. Vuku bi također bile izvađene oči, a mjesto njih u novije vrijeme stavljene su „franje” ili (špekule). Samog vuka napunili bi piljevinom ili slamom, a kolac i njega samog nakitilo bi se mašnom i papirnatim novcem. Uz lovca koji bi nosio vuka bio bi i lovac koji je nosio hrvatski barjak i njih nekoliko koji su se nazivali „torbarima” ili „torbašima” jer su nosili torbe ${ }^{24}$.

Dakle, lovci bi ušli u selo i od kuće do kuće pjevali pjesme, a seljani bi ih darivali - bilo novcem bilo hranom poput jabuka, dunja, jaja, slanine, pogače, a ponekad i terlucima i drugim.

U širokobriješkom kraju kada bi lovac ili netko drugi ubio vuka, nosio bi ga kroz selo radi isticanja hrabrosti i dobivanja darova zbog otklonjene opasnosti za stoku. Pastirice bi po cijeli dan bile kod ovaca, da ih ne bi napao vuk. Plele bi i prele i uz to pjevale. Pjesmom su tjerale strah od vukova.

Vučari bi išli od kuće do kuće i pred svakom bi kućom domaćinu rekli: „Faljen Isus”, a on bi im odgovorio: „Vazda Isus faljen bio!”. Svi bi

\footnotetext{
${ }^{22}$ Zapisala je svibnja 2006. g. Marina Matić u Trbounju kod Drniša, a kazao joj je Ive Matić (rođ. 1927. g). Rkp. FF ST sv. 2006., S.

${ }^{23}$ U Kruševu kod Zadra 2006. g. zapisala Marija Anić, a kazala joj je Stana Anić (djev. Anić, rođ. 1929. g. u Kruševu). Rkp. FF ST sv. 2006., S.

${ }^{24}$ Cf. I. Furčić, op. cit., str. 197.
} 
ukućani pohvalili lovce kako im je lovina dobra. Vučari bi govorili domaćinu: „Vidi li ti domaćine igdi vake mrcine?”. Svatko bi darovao što je imao, sira, slanine, bilo što, što se dobijalo od ovaca ${ }^{25}$.

Vučari su usput jeli, pili i pjevali. Taj se običaj zvao ,prositi s vukom". Vučari su pjevali:

Podaj vuku slanine

nek' ne silazi s planine.

podaj vuku šenice

nek ne kolje ovčice.

Podaj vuku svašta dosta,

nek ne kolje što nam osta.

Podaj vuku crna konca

ne otišla za udovca.

Evo vuka s planine,

podajte mu slanine,

da ne jede ovce u planine.

Podajte mu malo masla

na hiljade ovce pasla.

Goni vuka od kuće,

nije dobar kod kuće.

Podaj vuku varice,

nek ne kolje jarice.

Podaj vuku zelenila

u majke se rumenila.

Podaj vuku klip slanine,

Nek biži uz planine ${ }^{26}$.

U Doljanima kod Metkovića vučari su išli u lov na vukove, a kada bi ubili vuka pjevali bi:

Evo vuka s planine,

dajte njemu slanine.

Evo vuka preko mosta,

dajte njemu svega dosta.

${ }^{25}$ Zdravka Hrkać zapisala je 2010. godine u selu Oklaji kod Širokoga Brijega. Kazala joj je Vinka Skoko (djevojačko Čolak), 1931., Oklaji, Široki Brijeg. Rkp. FF MO sv. 2010., S.

${ }^{26}$ Ana Leko zapisala je 13. veljače 2010. godine u mjestu Njive, selo između Rasna i Dužica. Kazao joj je Šimun Brkić. Rkp. FF MO sv. 2010., S. 
Vučari su tom pjesmom od ljudi tražili dar, jer su ubili vuka i tako spasili ovce ${ }^{27}$.

U Ramljanima u Dalmatinskoj zagori kada bi netko ubio vuka, pozvao bi mještane koji najbolje znaju pjevati. Zajedno bi oderali vuka, osušili „mišinu” koju bi potom napunili slamom i nataknuli na kolac. To bi imitiralo vuka. Njega je nosio jedan čovjek kojega su pratila trojica s pjesmom. Tako su išli kroz selo, od kuće do kuće, i pjevali. Za njima bi trčala djeca i rugala se vuku. Domaćini bi ih častili jer je ubijanje vuka, koji je selu činio samo štetu, mnogo značilo. Ako bi u kući bila mlada djevojka za udaju, pjevalo bi se:

Evo, neve lipa struka,

darovat će našeg vuka.

Doša vule iz planine,

podajte mu klip slanine,

podajte mu dva tri jajca,

da ne kolje konja vranca.

Darujte mu runo vune,

da ne kolje ovce žune.

Podajte mu varćak žita,

i još što zapita.

Idući od kuće do kuće uglavnom su mijenjali prva dva stiha, prilagođavajući ih domaćinu. Na primjer, ako bi došli pred kuću seoskoga uglednika, prva dva stiha glasila bi:

Evo dvora poštenoga,

domaćina veseloga ${ }^{28}$.

U Mostarskom Gradcu običaj darivanja vučara odvijao se kroz dija$\log$ :

- Eej, domaćine!

- Eej!

- Faljen Isus, moj lipi domaćine!

- Vazda Ime njegovo.

${ }^{27}$ Branka Despotušić zapisala je 2007. godine u Doljanima kod Metkovića. Kazao joj je Mijo Raić, rođ. 1957. godine u Zahumlju, a sada živi u Pločama. Rkp. FF ST sv. 2007., S.

${ }^{28}$ Ana Sedlar zapisala je 2005. godine u Splitu. Kazao joj je njezin djed rođ. 1933. god. u Ramljanima, zaselak Sedlari, a od 1961. god. živi u Splitu. Rkp. FF ST sv. 2005., S. 
- ك̌ta to mi radiš, moj kume?

- Evo malo ovo krđe križam, šta ću, moram štogod zapalit. A šta to mi vi nosite, kume?

- A, vidiš ti, moj kume, kakvu ti mi lovinu nosimo prid kuću.

- A vala, eto od kad je mog vika, ja ti nisam vidija boljeg.

- A, moj kume, dugo se neće vidit vaki ulov.

- Pravo mi kaži di ga ubište?

- A ma šta ću ti brte ja pričat, moj kume, eno gori podno Veliki Bili, onden ispod Matanova vrtla.

- A pravo, nako od vas sedan, ko je imo bistro oko, a sigurnu ruku?

- Iko, brte, Matanov. Nemam ti ja šta pričat ni lagat.

- E vala svaka čast, ovo ja za velika dara brate.

- Je brte za velika dara i za velike pisme i za velike igre.

- E ajmo, brate mlađarijo, da se malo zaigra i zapiva.

- E oćemo, moj kume, dašta ćemo. A mi stari ćemo malo popit vina i malo rakije.

- Dakako, dakako. Ajde mlađarijo! ${ }^{29}$.

Vuk je bio prisutan i u razgovoru pastirica:

- Uuuu,vidiš li mi bona ovce, kažu da se vuk pojavija?

- Ehej, čobanice, ne boj se! Ubili su vuka.

- A di su ga ubili?

- Gori negdi podno Veliki Bili.

- A zna li se ko ga ubi?

- Kažu Iko Matanov.

- E neka Bogu vala.

- Neka, neka ${ }^{30}$.

U Kijevu kada je nekome pošlo za rukom da ubije vuka, skupilo bi se sedam-osam odraslih muškaraca te bi obilazili selo noseći prepariranog vuka. Najprije bi vuku oderali kožu, nabili bi je slamom, u noge bi mu utisnuli štapove kako bi mogao stajati, zube bi oderali vilicama i metnuli mu žvale te bi mu uz to stavili u usta crvenu jabuku tako da mu se dobro vide zubi. Vuk bi inače bio nabijen na jači štap, da bi ga vučari lakše mogli nositi kroz selo, od zaselka do zaselka. Vuk bi bio dobro iskićen: uzduž preko leđa povučena je pređa, a o nju su okačene šarolike rese od pređe.

${ }^{29}$ Anita Nogalo zapisala je u veljači 2010. godine. Kazali su joj članovi HKD Vrila, župa Mostarski Gradac, veljača 2010. Rkp. FF MO sv. 2010., D.

${ }^{30}$ Ibidem. 
Bilo bi tu i ručnika, rubaca, vunenih čarapa, torbica i slično, već prema tome kako tko od suseljana stavi na vuka svoj dar.

Među vučarima obavezno je morao biti jedan ili dvojica koji znaju dobro pjevati izventavat' (izmišljati pjesme). Vučari bi hodali obučeni u „kisnu” (običnu, svakodnevnu) nošnju. Čim bi se pojavili, u selu bi se odmah poručivalo: „Eto vučara! Eto vučara!”. Idući i pjevajući od kuće do kuće, vučarima je bio glavni motiv darovi koji su bili neka vrsta nagrade za ubijanje vuka i oslobađanje sela od štetne zvijeri ${ }^{31}$. Najčešći napjev bio je: Ajde gazda Marko, / davaj vuku slanine, / da ne silazi sa planine ${ }^{32}$.

Najčešći su darovi bili: komad slanine, žito, sol, vunene čarape, vuna, ručnik itd. Vučari bi dolazili u svako doba godine, a mještani bi ih častili vinom, ali se ono nije davalo $\mathrm{kao} \mathrm{dar}^{33}$.

U selu Nisko u Dalmatinskoj zagori kad bi lovac ubio vuka, trebao je dobiti dopuštenje od odbora da ga smije nositi po selima. Kad bi dobio dopuštenje, nosio bi ga po selima i kad bi došao pred čiju kuću, on i momci što su išli s njim pjevali bi:

Evo vule iz planine,

pita kruva i slanine.

Dajte vuli malo vune,

da ne kolje vaše žune.

Dajte vuli mkoje jajce,

da ne kolje vaše janjce.

Dajte vuli malo vina,

doša van je iz daljina.

Lovac je nosio barjak koji je na sebi imao roščiće (to je zapravo bilo veliko deblo s malim granama). Na te bi roščiće lovac stavljao sve što su mu ljudi davali te bi im pjevao:

${ }^{31}$ Jelena Vrcelj zapisala je 2010. godine u Kijevu. Kazao joj je Ivan Antunović rođen 30. studenog 1948. u Kijevu. Oženjen je i otac troje djece, živi u Kijevu. Rkp. FF ST sv. 2010., S.

${ }^{32}$ Sanja Barešić zapisala je 2010. godine. Kazao joj je Božo Jurić (rođen 12.08.1942.) rodom iz Kijeva.

${ }^{33}$ Jelena Vrcelj zapisala je 2010. godine u Kijevu. Kazao joj je spomenuti Ivan Antunović. Rkp. FF ST sv. 2010., S. 
Lipo ste nas darovali

od Boga se radovali ${ }^{34}$.

U vučarskoj basmi zapisanoj u selu Umčane 2010. godine vuka se podmićuje slaninom i mesom samo da ga se ne razljuti te da on ne silazi s planine.

Dajte vuku slanine,

da ne slazi s planine.

Dajte vuku mesa,

da nam ne bedesa ${ }^{35}$

Slijedi nekoliko basmi iz Planjana Gornjih, u selu Jurićima:

Iđe vule priko polja,

ubija ga Skejo Tolja.

Ubija ga iznenada,

kod Matetića vinograda!

ili:

Darujte nam našeg vulu,

da ne pravi štetu po guvnu!

Darujte nam dva, tri jajca,

da ne kolje konja vranca!

Darujte mu runo vune

da ne kolje ovce žune!

Ako se u nekoj kući domaćin namjerno ne bi odazvao ili ga ne bi zbilja bilo, otpjevali bi mu:

Izgubija vule oko,

sakrija se gazda Joko!

Ako bi ukućani izišli iz kuća, a vučare ne bi, najčešće iz neimaštine, darovali, otpjevalo bi im se na primjer:

Vule crn, napopriko gleda,

šta mu jednu jabuku ne da!

${ }^{34}$ Mandica Vujina zapisala je 2010. godine u selu Nisko u Dalmatinskoj zagori. Kazala joj je Manda Matas (djevojački Maleš, rođ. 1939. g.). Rkp. FF ST sv. 2010., D.

35 Antonija Gašpar 2010. Kazao je spomenuti Mate Gašpar rođen 10. lipnja 1947. u Umčanima. Rkp. FF ST sv. 2010., D. 
Iako je narod bio siromašan, darivati se nije oklijevalo. Jednako, ako ne i više, kao i „mačkare” nastojalo se darivati jer je zagoranski čovjek poznat po gostoljubivosti, ali i zahvalnosti lovcima koji su spasili njihova domaćinstva od još veće nevolje. Jedno vrijeme država je plaćala lovcima za ubijene vukove, a danas to isto kažnjava jer su vukovi u izumiranju. Spletom okolnosti taj rijedak i vrijedan običaj, zajedno s vukovima, doslovce je izumro.

U navedenim primjerima ophod vučara mogao bi se nazvati ,putujućim kazalištem" jer scenski prostor nije fiksiran, a glumci amateri, ovisno o prigodi, izvode svoju igru u dvorištima ili ispred raznih kuća koji su zapravo u službi stalnih ambijenata.

Glumci su isključivo muškarci koji u ovim prigodama putuju i u kilometrima udaljena sela. Oni ,glavniji” su izabrani za takve, zbog svoje odvažnosti i snalažljivosti, a i sklonosti humoru i dosjetljivosti. U usmenoj drami kažu da nije potvrđen redatelj. Međutim pred očima je čovjek kojeg seljani - glumci smatraju ,pametnim čovikom” i koji bi sve njih i cijelu igru mogao uskladiti, vođa koji će reći „što bi najbolje bilo”36.

\section{Vuk u drugim ophodima, običajima i vjerovanjima Hrvata}

Iz brojih ophoda, običaja i vjerovanja povezanih s vukom izdvojit ćemo samo tri primjera. Zanimljiv je ophod Svatovskih vukova. Taj je ophod činila skupina muškaraca, u pravilu neženja, koji nisu pozvani na svadbu, ali domaćini su za njih pripravljali hranu i piće. Ophod Svatovskih vukova zadržao se do sedamdesetih godina. Dok su vučarski ophodi uglavnom iščezli, u Deževicama se do naših dana sačuvao prastari ophod „vukova” na pokladni utorak. Pokladni vukovi u Deževicama traju dugo i datiraju iz vremena koja današnje stanovništvo i ne pamti. Nisu se održavali samo za vrijeme Domovinskog rata. Znatno kraću povijest ima Vučindan koji se tradicionalno na blagdan Spasova održava od polovice dvadesetoga stoljeća u brdskim metkovskim krajevima gdje se narod većinom bavio

${ }^{36}$ Kristini Jurić kazao je Josip Jurić (Markuzin) rođen 1933. u Planjanima. Rkp. FF ST, sv. 2009. D. 
stočarstvom. U brdskom dijelu župe u to su se vrijeme pojavili vukovi koji su mještanima pravili velike štete. Ni lovci, ni hajke na vukove nisu mnogo pomagali. Mještanima je to dojadilo te su utekli zagovoru svetoga Ivana Krstitelja svoga zaštitnika.

Posebnu vrstu usmene tradicije predstavljaju demonske predaje o $v u$ kodlacima. Pripovijedaju o mrtvacima koji su zbog teških grijeha četrdeset dana nakon smrti ustajali iz groba. Ako su za života bili pijanice, pojavljivali su se kao mješina puna vina, a ako nisu bili pijanice, pojavljivali su se u obliku mješine pune vodom. Nestajali bi kada bi bili probodeni glogovim kocem (ili sa sedam glogovih kolaca). U nekim krajevima (primjerice Hrvatskomu zagorju) vjerovalo se da će se pokojnik povukodlačiti ako preko njega prijeđe mačka.

Kudlaci su zli i uvijek nastoje naškoditi čovjeku, a često uzimaju različite životinjske oblike. Prema pričama oni se okupljaju na raskrižjima putova od dvadeset tri do dvadeset i četiri sata. Stoga se vjerovalo da nije dobro da se čovjek u to doba zatekne na putu jer bi mu se moglo dogoditi svakakvo zlo. Zbog toga se na raskrižjima putova postavljalo raspelo kao obrana od zlih sila, ali i pomoć u rasuđivanju pravih smjerova putovanja.

U Vinišću kod Trogira vjerovalo se u kodlake (vukodlake) koji su posebno mogli naškoditi djeci, pa kad bi djeca, a i odrasli, hodali noću (pogotovo kraj groblja), držali bi palac u ruci i tri puta izgovarali: ,Zapori kozlakov. / Isus prid nan, / Gospe za nan” ili: „Isusova brado, / Marijino mliko, / tri mise Božićne, / tri mise Uskrsne, / slavno sveto Vodokršće"37.

Mnogobrojne su demonološke predaje koje informanti i danas kazuju. Ta tema iziskuje posebnu znanstvenu obradbu.

\section{Zaključak}

Tridesetak suvremenih izvornih terenskih zapisa u ovom radu svjedoči iznimno mjesto koje pripada vuku u folkloru Hrvata. Do Domovinskoga rata, 1991. godine, u mnogim mjestima izvodili su se vučarski ophodi. U nekim su mjestima ti ophodi nazivani vukarski. Do tih ophoda dolazilo

\footnotetext{
${ }^{37}$ Ivan Marić, travnja 2006. g. u Vinišću kod Trogira, zapisao je po kazivanju bračnoga para Joze i Zorke Marić. Jozo je rođen u Vinišćima 1932. god., a Zorka 1936. god. u Okrugu Gornjem. Rkp. FF Split, 2006., S.
} 
je kada bi netko ubio vuka. Tada bi vuku oderali kožu, nataknuli je na veliki jači štap i napunili je najčešće slamom. Na vrhu štapa bila bi glava, a u vučje žvale stavili bi jabuku kako bi bolje do izražaja došli vučji zubi. Tada bi onaj koji je ubio vuka s još tri do četiri muškarca krenuo kroz selo, od kuće do kuće. Pred kućama bi pjevali/recitirali basme koje su imale apotropejski obred. Domaćini su ophodnike rado primali i nagrađivali jer su ubili vuka koji je nanosio veliku štetu.

Basme, ophodi i vjerovanja vezana uz vuka u sebi sadrže riznicu antropološkoga, etnološkog i filološkog blaga. Tako primjerice, u velolučkoj igri Vuki i ovce zanimljiv je genitiv množine s nastavkom -ah. Nominativ množine od imenice vuk glasi vuki. Sačuvan je i arhaični prezent gre (ide).

\section{Izvori}

Rkp. FF ST (Rukopisne zbirke Katedre za Hrvatsku usmenu književnost, Filozofskoga fakulteta Sveučilišta u Splitu).

Rkp. FF MO (Rukopisne zbirke Katedre za Hrvatsku usmenu književnost, Filozofskoga fakulteta Sveučilišta u Mostaru). Te su rukopisne zbirke nastale kao rezultat izvornih terenskih zapisa studenata kojima sam bio mentorom pri izradi seminarskih, završnih i diplomskih radova iz Hrvatske usmene književnosti i Hrvatske tradicijske kulture u europskom kontekstu.

(Oznaka D - znači diplomski rad, Z - znači završni rad, S - označava seminarski rad. Rukopisne zbirke nalaze se kod mene). 
